\title{
FUSIFORM ANEURYSMAL DILATATION OF THE PORTAL VEIN
}

ANTHony J. Leonsins, F.R.C.S.E.

ShIRLEY SieW, M.B.(RAND)

University of Witwatersrand, Medical School

A variety of pathologic changes may be associated with Banti's syndrome. These may include cirrhosis of the liver, splenic vein thrombosis, cavernomatous transformation of the portal vein and aneurysm of the splenic artery. However, a protracted search of the literature revealed no case of fusiform aneurysm of the portal vein as a result of an enlarged, congested spleen and liver cirrhosis. As the following case is one of unusual interest we are briefly reporting the clinical course and the pathological findings.

\section{Case Report}

Mr. P.E.C., a truck driver, aged 52 years, was admitted to the General Hospital, Johannesburg, South Africa, on July 29, I95I, with the diagnosis of infective hepatitis. Two days prior to admission he had developed marked anorexia and extreme weakness. He passed dark urine and noted the onset of jaundice; this was the fifth occasion that he had become jaundiced in the past 32 years.

\section{Past History}

Jaundice first occurred at the age of 19 years but he was well until 1930, when, aged 3 r years, he had a small haematemesis. At this time a large spleen was discovered and the diagnosis of Banti's syndrome was made.

In 1943, whilst in a military hospital in Pretoria, he had two further severe episodes of haematemesis and he was discharged from the services with the diagnosis of Banti's splenomegaly with hepatomegaly. In 1949, he was admitted to the General Hospital, Johannesburg, with sudden severe abdominal pain which subsided after two weeks. No operation was advised. He had an icteric index of 56 , and total bilirubin $10.8 \mathrm{mg} . / 100$ $\mathrm{ml}$. Just over two years later he was re-admitted with the same complaint. Prior to this admission he was in good health and was gainfully employed.

Family History; Nil contributory. Habits; 25 cigarettes daily. Two brandies and one pint beer per day. Weight; Steady-averaging $140 \mathrm{lb}$. Central Nervous System; Excellent vision and no headaches or episodes of drowsiness or uncontrolled social behaviour. Cardiovascular System; Breathlessness on exertion for the past four or five years. No ankle oedema.

Physical Examination; Drowsy, deeply jaundiced, middle-aged male; not dyspnoeic and no clubbing of the fingers; blood pressure 120/50; pulse 108; temp. IOI. ${ }^{\circ} \mathbf{F}$;; spider naevi on cheeks and palmar erythema.
Chest, Nil of note. Nipples not enlarged. Abdomen; 3 Easily palpable, enlarged, hard, non-tender spleen $\dot{\omega}$ extending to the right of the umbilicus. Liver enlarged -about two fingers: surface granular and non-tender; $\doteq$ no ascites. There were bilateral indirect inguinal 6 herniae. There were no other positive physical findings. O Total bilirubin $10.2 \mathrm{mg}$./100 ml. Icteric index 60 . O Albumen $3.0 \mathrm{mg}$. and globulin $3.7 \mathrm{~g} . / 100 \mathrm{ml}$. Thymol 응 Flocculation Test: ++++ . Takata-Ara:.$+++ \supset$ Haemoglobin 15.I g. \%. Prothrombin index $48 \%$. $\overrightarrow{0}$ Barium Meal showed well-marked oesophageal varices. $\mathbb{D}$ After five days the jaundice was no longer visible but 0 he was still very drowsy. On August 9, I95I, he passed a large tarry stool. Papilloedema was present and spot taneous purpura developed. A 500-ml. blood transfusio $\mathbb{D}$ was administered and patient rallied. Thymol tue bidity 7 units; Thymol Flocculation ++ ; Takata $\overrightarrow{0}$ Ara reaction +++ ; Serum Bilirubin $($ Direct) $=2.98 \%$ mg./100 ml.; Total Bilirubin $=4.8 \mathrm{mg} . / 100 \mathrm{ml}$ Alkaline Phosphatase 7 K.A. units; icteric index 30 .

August 15, 1951. Further melaena stools at which time $\mathrm{Hb}$. dropped to $6.4 \mathrm{~g} . \%$ and $\mathrm{I}, 000 \mathrm{ml}$. of packed red cells were transfused.

August 21, 195I. The right parotid gland was obviously enlarged, rubbery on palpation but nontender. Patient was very lethargic but non-complaining.

August 23, 195 I. Another $500 \mathrm{ml}$. blood transfused. No jaundice noted.

August 24, 1951. Abdomen very distended and marked fluid thrill present. Further $\mathrm{r}, 000 \mathrm{ml}$. of whole blood transfused and 2,700 ml. of ascitic fluid aspirated from peritoneal cavity.

August 28, 195 I. Massive melaena. 2,000 ml. blood transfused. $500 \mathrm{ml}$. plasma and Vit. $\mathrm{K}$ administered. Gross oedema of the genitalia was present, but ankles and legs were non-oedematous.

August $30,195 \mathrm{I}$. Another transfusion of $1,000 \mathrm{ml}$. blood was necessary. After $1,300 \mathrm{ml}$. of ascitic fluid had been drained pre-operatively, Drs. Lee McGregor and Leonsins performed an emergency splenectomy through a thoraco-abdominal approach. The liver. was shrunken to about 6 in. in diameter and was nodular and $\mathrm{N}$ fibrotic. On the first post-operative day patient appeared very well.

September I, 195I. Slight jaundice was apparent. N Heparin 5,000 units was administered every six hours.

\section{Histology of Spleen}

The spleen was a massively enlarged, firm organ, $\mathbb{D}$ weighing $3,150 \mathrm{~g}$. The histology showed the presence ? of well-marked fibrous thickening of the capsule and $T$ trabeculae. There was also extensive fibrosis of the 


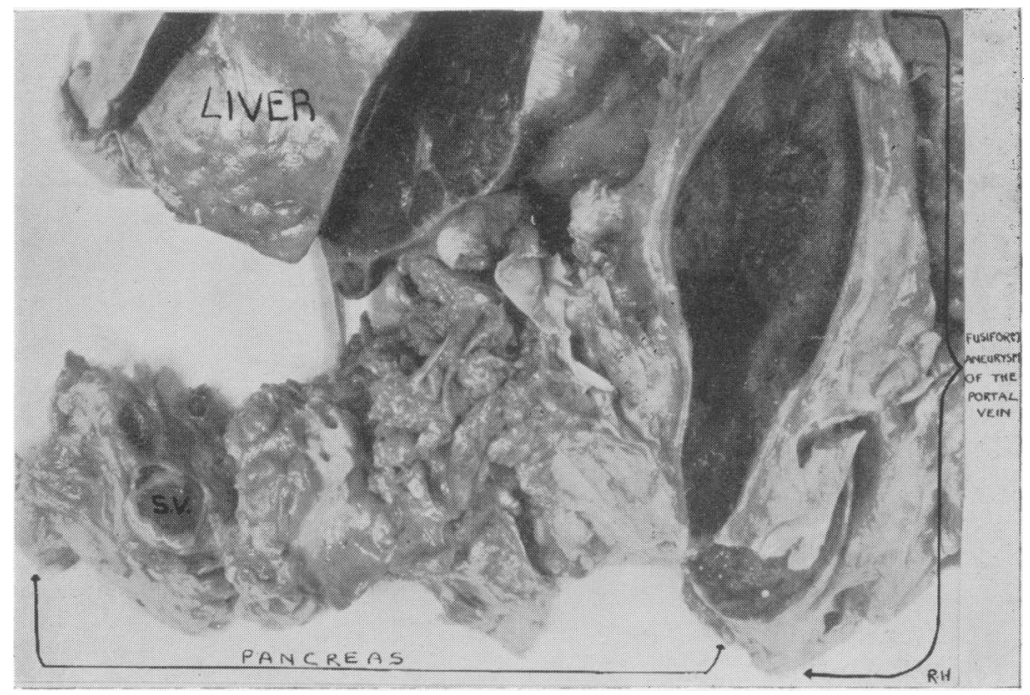

Fig. I.-The lower border of the liver is seen in the upper left-hand corner. The hepatic capsule is thickened and the surface shows an irregular nodularity. The liver has been incised and the cut surface presents a coarse irregular cirrhosis with broad bands of fibrous tissue traversing the liver substance in an irregular manner. Coming down from the porta hepatis to the head of the pancreas along the right border of the photograph is the fusiform aneurysm of the portal vein. The base of the aneurysmal sac projects below the lower edge of the pancreas. The wall of the sac is thickened and it is filled with ante-mortem thrombus. The pancreas is seen along the lower portion of the photograph and, in relation to its tail, there is present the dilated, thrombosed splenic vein.

splenic pulp and dilatation of the sinusoids. In addition, foci of haemorrhage and 'Gamna-Gandy' nodules could be seen. The histological features were consistent with those of a splenomegaly of the Banti's syndrome type.

The liver biopsy showed a moderate degree of periportal fibrosis with which was associated a round cell infiltration. Bile thrombi were present in some of the smaller canaliculi. There was an increase of the pigment within the liver cells.

September II, 195r. All the wound sutures were removed but unfortunately 3 in. of the wound gaped open and this necessitated re-suturing.

September 12, 195I. The greater portion of the wound burst open and this too had to be re-sutured. B.P. 100/80. Pulse I Io. A large left pleural effusion developed.

September 18, 1951. Patient was quite cheerful and much improved. The wound was oozing large quantities of serous discharge and healing was poor.

September 19, 195 I. Two melaena stools and a small haematemesis. (Hb. I1.4 g.\%. B.P. 120/70.) I,000 ml. blood transfused.

September 23, 195 I. Patient very anaemic; 2,000 ml. blood given into the sternum, as most of the accessible veins were thrombosed. During the period patient was given high doses of Vitamin B complex, methiscol and chloramphenicol.

September 24, 195I. A second operation was performed by Mr. Lee McGregor. A vitallium tube was inserted via the external abdominal ring between the peritoneal cavity and the thigh in order to drain the ascitic fluid into the lower limb tissue lymphatics. After completion of this minor procedure a right subcostal incision was made and after exposure of the free edge of the lesser omentum the main hepatic artery was exposed and ligated. At the conclusion of this operation the patient's condition appeared satisfactory.

September 29, 195I. A large melaena stool was passed and the patient's condition deteriorated rapidly. Despite many blood transfusions and other supportive therapy the patient died on October 5, I 95 I.

\section{Autopsy Findings}

The autopsy was performed by one of us (S.S.) seven hours after death. The principal findings were:

The heart was slightly enlarged $(390 \mathrm{~g}$.). All the valves were competent and healthy. The myocardium was pale and flabby and the endocardium of the left ventricle was thickened. The coronary arteries were healthy. There was fatty streaking in the commencement of the aorta and moderate atheroma in the abdominal aorta. The oesophagus showed grossly distended varicose veins, extending three quarters of the way up from the cardiac end. The stomach was contracted; it contained an abundant quantity of altered blood and the mucosa showed a chronic hypertrophic gastritis. Blood staining of the intestinal mucosa was seen throughout the length of the rest of the tract. The liver was diminished in size and was deeply bile stained. Its surface was grossly irregular due to a coarse nodularity. On section, an irregular coarse cirrhosis was present. Scattered throughout the liver were small pale areas of necrosis. Thrombosis was present in the hepatic artery. The gall bladder was very flabby owing to gross oedema of its wall. There was no evidence of extra-hepatic obstruction as a probe could be passed with ease from the ampulla up the common bile duct. The 


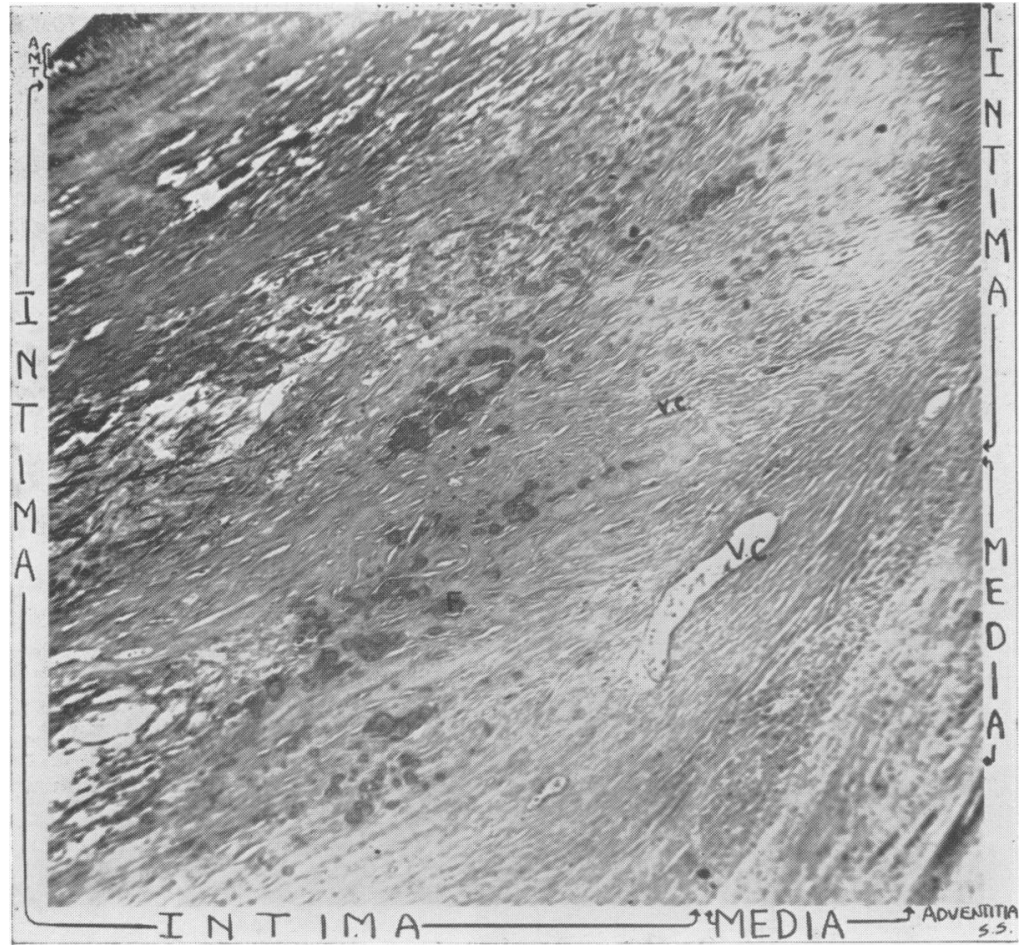

FIg. 2.- Section of the portal vein, stained by the haematoxylin and eosin method. Ante-mortem thrombus is present, intimately adherent to the intima. The intima can be seen to be grossly thickened and to occupy the bulk of the wall. In the more superficial layers there is loosening and degeneration but in the deeper layers the fibrous tissue becomes more dense. Many vascular clefts (v.c.) and plugs of fibrin (f) are present. The media is thinned and atrophic. There is fragmentation of the internal elastic lamina.

pancreas was increased in consistency and on section a large aneurysinal sac containing ante-mortem thrombus was found in relation to the head of the pancreas. On dissection, this proved to be the portal vein which had undergone aneurysmal dilatation. The sac was $8 \mathrm{~cm}$. long and $4 \mathrm{~cm}$. wide and extended from the porta hepatis to the inferior border of the pancreas (Fig. I). The splenic vein was also dilated and thrombosed throughout its course in relation to the pancreas.

\section{Histopathology}

Sections of the portal vein (Fig. 2) showed well marked thickening of the intima which formed the greater part of the wall of the vein. The intima showed layers of dense fibrous tissue, poor in nuclei, separated by spindleshaped clefts lined by endothelial cells, i.e. vascular spaces, thus indicating a mild degree of cavernomatous transformation. An ante-mortem thrombus was intimately adherent to the luminal surface of the intima and localized foci of fibrin deposit were found within the fibrous tissue of the intima itself. Special staining with the Weigert-van Gieson technique showed the presence of some longitudinal muscle fibrils in the intima and the internal elastic membrane was seen to be thinned and fragmented. Foci of calcification were noticed in the intima. The media was thinner than normal and in places extreme atrophy was present. There was $a_{3}^{3}$ diminution in the elastic and muscle fibres and an increase in the fibrous tissue (Fig. 3). Sections of the splenic vein showed the changes of phlebosclerosis and ante-mortem thrombosis as described above in the portal 3 vein, but the lesion was not so far advanced in this vessel.; Sections of the liver showed the presence of a coarse 3 irregular fibrosis of the portal tracts which had led to great distortion of the lobular architecture. However, $\mathrm{O}$ in some areas normal lobules could still be recognized. A large area of lobular necrosis was present and thereo were many foci of centri-lobular necrosis, some of which showed evidence of organization. Bile staining was well $\rightarrow$ marked, particularly in central zone and bile thrombi․ were seen in the intercellular canaliculi and in the cholangioles. The bile ducts in the portal tractsor showed no evidence of abnormality. These features are $\mathrm{N}$ those of a coarse cirrhosis of the 'post-necrotic scarring '응 variety, with evidence of acute intra-hepatic obstruction. $\mathrm{C}$ The areas of recent necrosis have followed ligation of the hepatic artery. Sections of the kidneys showed the presence of lower nephron damage with bile casts in the distal convoluted tubules. Sections of the lungs $₫$ showed the presence of congestion, some atelectasis and? foci of bronchopneumonia. Sections of the oesophagus $\square$ showed well marked distension of the vessels. 


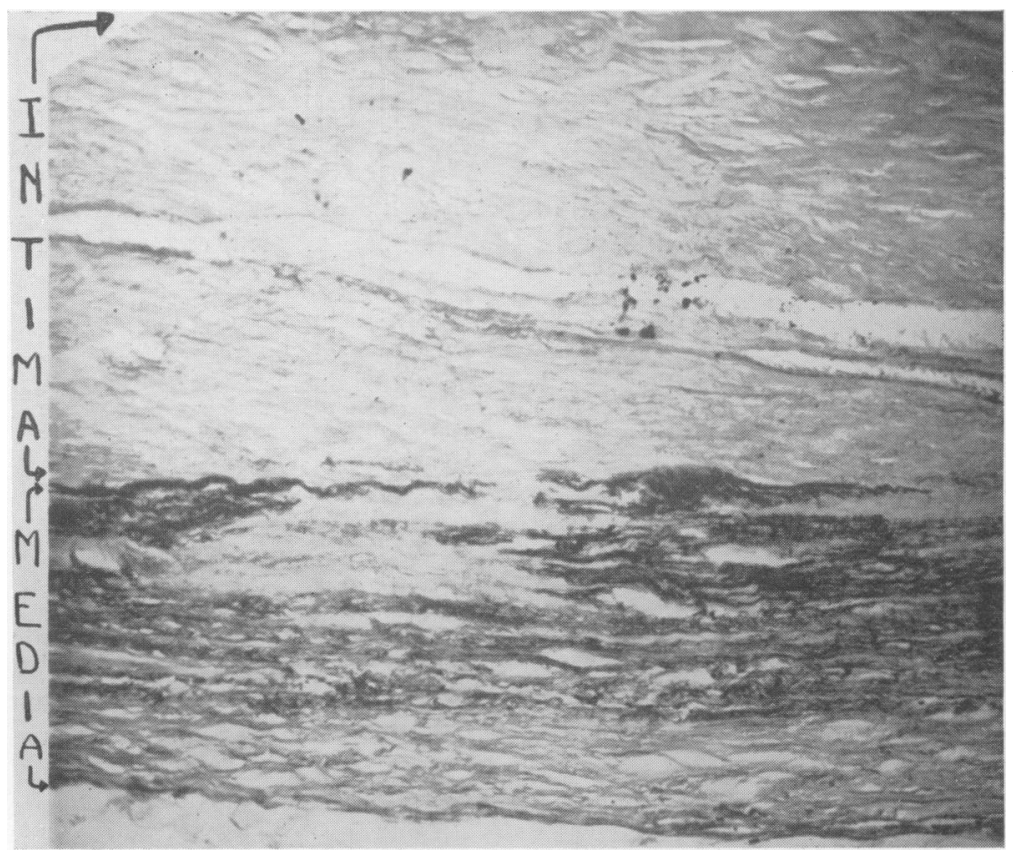

FIG. 3.-Section of the portal vein stained by the Weigert-van Gieson method. The dense fibrosis of the deeper layers of the intima is well shown. In the media the fragmentation of the elastic tissue is clearly demonstrated.

\section{Discussion}

Douglass, Baggenstoss and Hollinshead ${ }^{7}$ measured the portal vein in 92 dissections. Their results were as follows:
Average Diameter $\quad$. $\quad \ldots \quad 0.89 \mathrm{~cm}$.

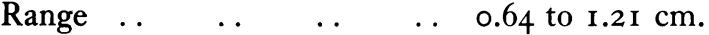
Average Length $\quad$. $\quad \ldots \quad 6.4 \mathrm{~cm}$.
Range .. $\quad \ldots \quad \ldots \quad \ldots \quad 4.8$ to $8.8 . \mathrm{cm}$.

Purcell14 found the average diameter to be $1.09 \mathrm{~cm}$. Child ${ }^{6}$ states that in cases of hepatic cirrhosis a portal vein with a diameter of $2 \mathrm{~cm}$. has been found. It can thus be seen that the portal vein in this case was grossly dilated, reaching aneurysmal proportions as the sac measured $4 \mathrm{~cm}$. in diameter. The aneurysm was of the fusiform morphology and involved the entire length of the portal vein.

Careful searching through the literature ${ }^{1,11,17}$ failed to disclose a similar case and, on personal questioning, Prof. Sheila Sherlock, Dr. Robert Linton, Dr. Paul Steiner, Dr. Bax and Dr. Schlamm all declared that in their experience they had never encountered a case of an aneurysm of the portal vein. Barzilai and Kleckner ${ }^{3}$ reported a saccular aneurysm of the right branch of the portal vein which ruptured into the common bile duct producing a haemocholecyst in a case of postnecrotic cirrhosis with thrombosis of the portal vein.

Histologically the portal vein showed well marked phlebosclerosis and ante-mortem thrombosis.

Banti' 9 described a 'Sclerosing Endophlebitis' affecting especially the splenic, less frequently the portal and infrequently the mesenteric veins, in association with the Banti spleen ( 1898 and I9I0).

Simmonds ${ }^{18}$ found thickening of the intima of the portal vein, with calcification and hyaline change, in association with cirrhosis of the liver and syphilis. Since then portal phlebosclerotic changes have been reported repeatedly in cases of portal hypertension. In 1942 Moschowitz $^{13}$ wrote 'Sclerosis of the veins of the portal system is perhaps the most commonly reported example of phlebosclerosis. It is nearly always associated with conditions that may cause obstructions of the portal veins, such as hepatic cirrhosis and portal thrombosis.'

$\mathrm{Li}^{10}$ gave a detailed description of the changes in the portal vein in cases of portal hypertension. Of his series of 26 patients changes were demonstrated in 20 , i.e. 76 per cent.- the lesions consisting of muscular hypertrophy of the media and intimal thickening with the development of longitudinal muscle fibres subintimally. In the stage of decompensation this medial myohypertrophy would fail and the muscle and elastic tissue would then be replaced by fibrous tissue and phlebosclerosis would result. In this stage Adami ${ }^{1}$ 
noticed an increase of connective tissue in all the layers with degeneration of the elastic tissue and remarked upon the fact that the connective tissue in the irtima was poor in nuclei. He described this vein lesion as being due to a strain fibrosis.

Benda $^{4}$ had mentioned fatty changes in the intima of the portal vein in hepatic cirrhosis and atheroma of the portal vein with ante-mortem thrombosis was described by Whiteley ${ }^{19}$ in the case of a 64-year-old woman who had a coarsely lobulated cirrhosis of the liver.

The possibility of sclerosis being secondary to hepatitis which spread into the portal vein is discussed by Magovern and Muehsam. ${ }^{12}$ Primary sclerosis of the portal vein was reported by Reich, ${ }^{16}$ Buday, ${ }^{5}$ Hart, ${ }^{8}$ Winkler, ${ }^{20}$ and Redo and O'Sullivan. ${ }^{15}$

The case reported by Reich $^{\mathbf{1 6}}$ was that of an Italian women aged $2 \mathrm{I}$, who died with multiple thrombosis of the portal, superior mesenteric, left common iliac, external iliac, femoral, hypogastric and pulmonary veins, the submucosal veins of the small intestine and the veins of the lymph nodes. There was marked fibrous tissue proliferation and diffuse round-cell infiltration surrounding the thrombi with fraying, thickening and interruption of the internal elastic membrane. The possibility that the phlebosclerosis is not actually primary but is secondary to the thrombosis cannot be excluded in such a case as this.

Redo and O'Sullivan ${ }^{15}$ suggested that the etiology of the sclerosis of the portal vein in the two cases reported by them was not the portal hypertension, but rather that the sclerosis might have been the probable cause of the hypertension. This suggestion could be considered only in the second case discussed by them who showed no evidence of abnormality on biopsy of the liver but had sclerosis, calcification and probable thrombosis of the portal vein, a portal pressure of 200-2 IO mm. saline and oesophageal varices; but is hardly applicable to their first patient who had evidence of hepatic cirrhosis and splenomegaly I4 years before they operated on him and found calcification of the portal vein which prevented its use in a porto-caval shunt. At the present state of our knowledge one cannot minimise the finding of a definite cirrhosis in cases of portal hypertension and must accept it as being the primary cause of the hypertension which leads to compensatory medial myohypertrophy of the portal vein which would be followed by decompensation and phlebosclerosis.

The histopathology of the portal vein in our case showed it to be in an advanced stage of decompensation sclerosis with the subintimal longitudinal muscle fibrils being evidence of previous compensatory hypertrophy. This extreme fibrosis of the wall of the veins had caused gross weakenin and resulted in progressive dilatation of the port vein with the formation of an aneurysm. Ante mortem thrombosis had taken place within the aneurysmal sac. The vascular clefts and the deposits of fibrin seen in the intima indicated re् canalization and organization of these luming thrombi.

The following sequence of events must bo postulated: coarse atrophic cirrhosis of the liver (post-necrotic scarring) causing progressive portâl hypertension which led to (a) rupture of the oesophageal varices (b) splenomegaly (c) phlebar sclerosis of the portal vein leading to aneurysma dilatation and ante-mortem thrombosis.

\section{Summary}

A case of a fusiform aneurysm of the portal vern is described in a male aged 52 years who presenteg clinically with a Banti's syndrome and who hadca splenectomy. At autopsy a coarse irregula cirrhosis of the liver was found with evidence of portal hypertension-phlebosclerosis and aneurys mal dilatation of the portal vein.

\section{Acknowledgment}

We are indebted to Mrs. A. Vorster and Mrr Holloway for the microscopic sections and we $81 \mathrm{~s}$ wish to thank Mr. R. Holloway for photographire the specimen and Mr. A. Shevitz for the printơng?

Our gratitude is extended to Mrs. J. E. Bantley for secretarial assistance and for typing this artice and we thank Miss E. G. Lahner for transcribin the numerous articles of reference.

\section{REFERENCES}

I. ADAMI, J. G., ALLBUT, T. C., and ROLLESTON, F. 'System of Medicine.'

2. BANTI, G. (I910), Folio Haemat., 10, 33, Translated from Italian by Robert Tissot.

3. BARZILAI, R., and KLECKNER, M. S. (1956), A.M.A. Arch Surg., 72, 725 .

4. BENDA, C. (1924), 'Phlebosklerose Henke und Lubansckss Handbuch der speziellen pathologischen Anatomie un Histologie,' vol. ii, p. 83I, Berlin.

5. BUDAY, K. (1903), Zbl. allg. Path. path. Anat., 14, 161.

6. CHILD, C. G. (1954), "The Hepatic Circulation and Porta.1 Hypertension.' Philadelphia: Saunders.

7. DOUGLASS, B. E., BAGGENSTOSS, A. H., and HOLLINS HEAD, W. H. (1950), Surg. Gynec. Obstet., 91, 562.

8. HART, C. (1913), Berl. klin. Wschr., 50, 2231.

9. HOLMAN, S., 'Banti's Syndrome,' 'Thesis presented to the University of Witwaterstrand,' February, 1954 .

ro. LI, P.L. (1 940), F. Path. Bact., 50, 121.

I I. LICHTMAN, S. S. (I949), 'Diseases of the Liver, Gall Blad: der and Bile Ducts,' Ed. 2. Philadelphia: Lea and Febigef

12. MAGOVERN, G. J., and MUEHSAM, G. E. (1954), Amer. Roentgenol, 71, 84 .

13. MOSCHOWITZ, E. (1942), 'Vascular Sclerosis,' p. \& London, New York, Toronto: Oxford University Press.

14 PURCELL, H. K., CONNOR, J. J., ALEXANDER, W. F and SCULLY, N. M. (1951), A.M.A. Arch. Surg., 62, 670.

15. REDO, S. F., and

16. REICH, 73, 532. (1942), Arch. intern. Med., 69, I1 7.

16. REICH, N. E. (I942), Arch. intern. Med., 69, 117 . System.' Oxford: Blackwell Scientific Publications.

18. SIMMONDS, M. (191 2), Arch. Path. Anat., 207, 360.

19. WHITELEY, H. J. (1953), $\mathcal{F}$. Path. Bact., 66, 563.

20. WINKLER, H. (I9I 5), Frankfurt. Z, Path., $17,377$. 